\title{
Physical mechanism of strong negative storm effects in the daytime ionospheric F2 region observed with EISCAT
}

\author{
A. Mikhailov ${ }^{1}$, K. Schlegel ${ }^{2}$ \\ ${ }^{1}$ Institute for Applied Geophysics, 129128 Rostokinskaya 9, Moscow, Russia \\ 2 Max-Planck-Institut für Aeronomie, Max-Planck-Str. 2, D-37189 Katlenburg-Lindau, Germany \\ Fax: + 495556979 240; e-mail: schlegel@linmpi.mpae.gwdg.de
}

Received: 14 January 1997 / Revised: 2 December 1997 / Accepted: 12 December 1997

\begin{abstract}
A self-consistent method for daytime F-region modelling was applied to EISCAT observations during two periods comprising the very disturbed days 3 April 1992 and 10 April 1990. The observed strong $\mathrm{N}_{e}$ decrease at F2-layer heights originated from different physical mechanisms in the two cases. The negative F2layer storm effect with an $N_{m} \mathrm{~F} 2$ decrease by a factor of 6.4 on 3 April 1992 was produced by enhanced electric fields $(\boldsymbol{E} \approx 85 \mathrm{mV} / \mathrm{m})$ and strong downward plasma drifts, but without any noticeable changes in thermospheric parameters. The increase of the $\mathrm{O}^{+}+\mathrm{N}_{2}$ reaction rate resulted in a strong enrichment of the ionosphere with molecular ions even at F2-layer heights. The enhanced electric field produced a wide mid-latitude daytime trough on 03 April 1992 not usually observed during similar polarization jet events. The other strong negative storm effect on 10 April 1990 with a complete disappearance of the F2-layer maximum at the usual heights was attributed mainly to changes in neutral composition and temperature. A small value for the shape parameter $S$ in the neutral temperature profile and a low neutral temperature at $120 \mathrm{~km}$ indicate strong cooling of the lower thermosphere. We propose that this cooling is due to increased nitric oxide concentration usually observed at these heights during geomagnetic storms.
\end{abstract}

Key words. Atmospheric composition and structure . Thermosphere $\cdot$ Ionosphere $\cdot$ Ion chemistry and composition $\cdot$ Atmosphere interactions

\section{Introduction}

Ionospheric F2-layer negative storms have been studied for years and general mechanisms of their origin are well known. A comprehensive review on this problem can be

Correspondence to: K. Schlegel found in Prölss (1995). So far mid- and low-latitude F2layer storm effects have been studied more extensively than high-latitude ones. This is partly due to the difficulties with ground-based ionosonde observations during geomagnetically disturbed periods. In addition, the high-latitude $\mathrm{F} 2$ region is very variable, being strongly influenced by magnetospheric processes; in particular, substantial electric fields are usually present during geomagnetic storms. These electric fields and the corresponding horizontal $\boldsymbol{E} \times \boldsymbol{B}$ plasma drifts can strongly perturb the electron density distribution at F2-layer heights. Neutral composition and temperature changes are the other source of negative F2-layer storm effects. The aim of the present work is to study the physical mechanism and to estimate the contribution of various processes to the observed storm-time $N_{e}(h)$ changes. Two periods of EISCAT observations comprising the very disturbed days 03 April 1992 and 10 April 1990 with a very strong electron concentration depletion are analyzed in the paper.

These cases were chosen to demonstrate different physical mechanisms of the observed negative storm effect. The first case presents an isolated geomagnetic storm with a moderate $\mathrm{Ap}=32$ but a sharp and very strong upsurge in the westward $\boldsymbol{E} \times \boldsymbol{B}$ plasma drift around noon followed by a $N_{m} \mathrm{~F} 2$ decrease of a factor of 6.4 relative to the quiet prestorm day 02 April 1992. The other case of 10 April 1990 refers to an extremely severe geomagnetic storm with $\mathrm{Ap}=124$ when the F2-layer maximum practically disappeared at the usual heights and an electron concentration peak around $200 \mathrm{~km}$ constituted the ionospheric maximum. Similar effects were observed in the American longitudinal sector with the Millstone Hill incoherent-scatter radar on 10 April 1990 (Buonsanto et al., 1992): The daytime ionospheric densities were extremely low over the probed latitude range, and since the peak height was in the molecular ion-dominated region below $200 \mathrm{~km}$, the F2-layer maximum was in fact a F1-layer peak. The storm effects at Millstone Hill were studied by Mikhailov and Foster (1997). 
The EISCAT observations are analyzed in this paper with the help of the self-consistent method developed by Mikhailov and Schlegel (1997). It provides the set of main aeronomic parameters $\left([\mathrm{O}],\left[\mathrm{O}_{2}\right],\left[\mathrm{N}_{2}\right]\right.$, vertical plasma drift $W$, exospheric temperature $T_{e x}$, and the shape parameter $S$ for the neutral temperature height profile, which are altogether responsible for the formation of the $N_{e}(h)$ profile) and yields information about the physical mechanisms of the observed F2-layer storm effects.

The main aim of Mikhailov and Schlegel (1997) was to demonstrate that our method is very effective and yields valuable information about the ionosphere and thermosphere. In this investigation we apply our model to two specific examples of ionospheric storm events. Moreover, as a new feature in this study, neutral temperature at $120 \mathrm{~km}$ height was included to the set of fitted parameters, as it may differ from the values provided by the MSIS model during severe storm periods.

Our original method can be used when the F2-layer maximum is well defined. In this case some of the parameters can be found from fitting theoretical $N_{m} \mathrm{~F} 2$ and $h_{m} \mathrm{~F} 2$ values to the observed ones. On 10 April 1990 when the F2-layer maximum was absent, a different approach was used to find the solution. In this case all six aeronomic parameters $T_{e x}, S, T_{120}$, [O], $\left[\mathrm{O}_{2}\right],\left[\mathrm{N}_{2}\right]$ were varied to fit the observed $N_{e}(h)$ profile. The vertical plasma drift was calculated as in the previous method using the observed $V_{l}(h)$ and other parameters calculated in a self-consistent way in the $N_{e}(h)$ fitting procedure.

\section{Observations and model calculations}

A list of the available observations along with solar and magnetic indices used in the study is given in Table 1. The 3-month average solar index F10.7 was 151.7 and 187.9 for the two periods in question.

The April 1992 period is very suitable for the analysis as it includes three quiet days preceding the storm, so 2 April can be used as a quiet reference day. For the second period we do not have a similar quiet reference, but Millstone Hill radar observations for the same period (Mikhailov and Foster, 1997) show that the F2 layer was only moderately disturbed on 9 April 1990 with $N_{m} \mathrm{~F} 2$ reduced by a factor of 2 with respect to the nearest quiet day 7 April.

Table 1. Dates and geophysical parameters of the periods used in the study

\begin{tabular}{lcrlr}
\hline date & time (UT) & Ap & $\begin{array}{l}\text { F10.7 } \\
(\text { day/day-1) }\end{array}$ & $\begin{array}{l}\boldsymbol{E} \times \boldsymbol{B} \\
(\mathrm{m} / \mathrm{s})\end{array}$ \\
\hline 31 March 1992 & $1300-1400$ & 14 & $191.4 / 182.4$ & 250 \\
1 April 1992 & $1300-1400$ & 13 & $186.1 / 191.4$ & 150 \\
2 April 1992 & $1300-1400$ & 6 & $161.2 / 186.1$ & 50 \\
3 April 1992 & $1400-1500$ & 32 & $159.7 / 161.2$ & 1700 \\
9 April 1990 & $1400-1500$ & 34 & $146.3 / 151.9$ & 500 \\
10 April 1990 & $1315-1415$ & 124 & $148.7 / 146.3$ & 700 \\
\hline
\end{tabular}

The EISCAT CP-1 program provides range profiles of $N_{e}, T_{e}, T_{i}$ and $V_{l}$ with the antenna beam directed along the local geomagnetic field line. We used the longpulse data for our purpose in the form as distributed by EISCAT (integration time 5 minutes, standard profile of $\left[\mathrm{O}^{+}\right] / N_{e}$ ). We calculated median profiles over about an hour (12-13 values, see Table 1) for each of the four parameters with standard deviations at each height. Data with finer height resolution from an alternating code pulse scheme for $\boldsymbol{E}$ and lower $\mathrm{F}$ regions were analyzed as well, but they were not used in the study (see Sect. 3).

On 3 April 1992 a steep upsurge of the westward $\boldsymbol{E} \times \boldsymbol{B}$ drift started after 1000 UT, peaked around 1200$1400 \mathrm{UT}$ at values of about $2000 \mathrm{~m} / \mathrm{s}$, and then subsided down to $1000 \mathrm{~m} / \mathrm{s}$. Therefore we accepted a mean value of $1700 \mathrm{~m} / \mathrm{s}(\boldsymbol{E} \approx 85 \mathrm{mV} / \mathrm{m})$ for the analyzed period 1400-1500 UT. On 10 April 1990, strong $\boldsymbol{E} \times \boldsymbol{B}$ drifts were observed during the whole day. A northwest drift of $700 \mathrm{~m} / \mathrm{s}(\boldsymbol{E} \approx 35 \mathrm{mV} / \mathrm{m})$ was observed during the analyzed period $1315-1415$ UT.

In Figs. 1 and 2 we present observed $N_{m} \mathrm{~F} 2$ and $h_{m} \mathrm{~F} 2$ variations during daytime hours for the two periods. The disturbed day 3 April is characterized by an increase in $h_{m} \mathrm{~F} 2$ and a strong decrease in $N_{m} \mathrm{~F} 2$ in comparison with the previous quiet days. Such $h_{m} \mathrm{~F} 2$ and $N_{m} \mathrm{~F} 2$ variations are similar to mid-latitude negative F2-layer storm effects resulting from changes of neutral composition and temperature (see for instance Prölss, 1995). In
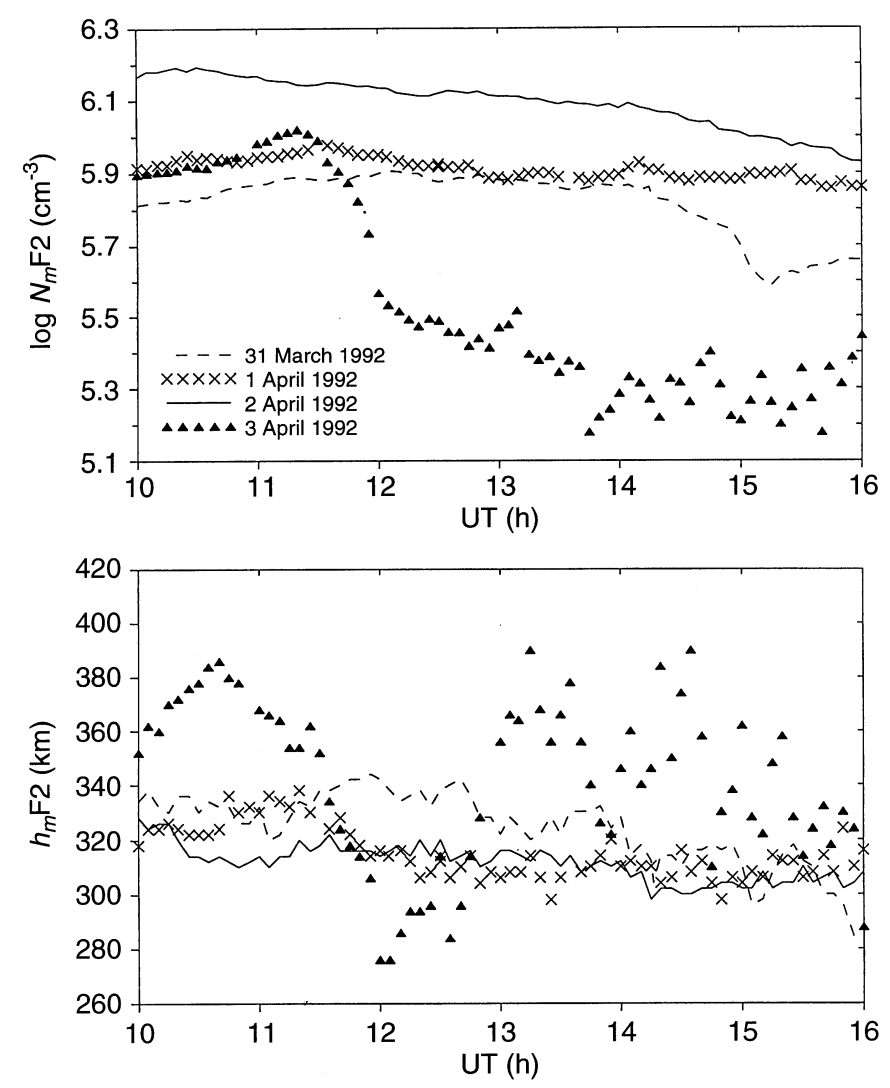

Fig. 1. Observed $N_{m} \mathrm{~F} 2$ and $h_{m} \mathrm{~F} 2$ variations for 31 March to 3 April 1992 during daytime hours 

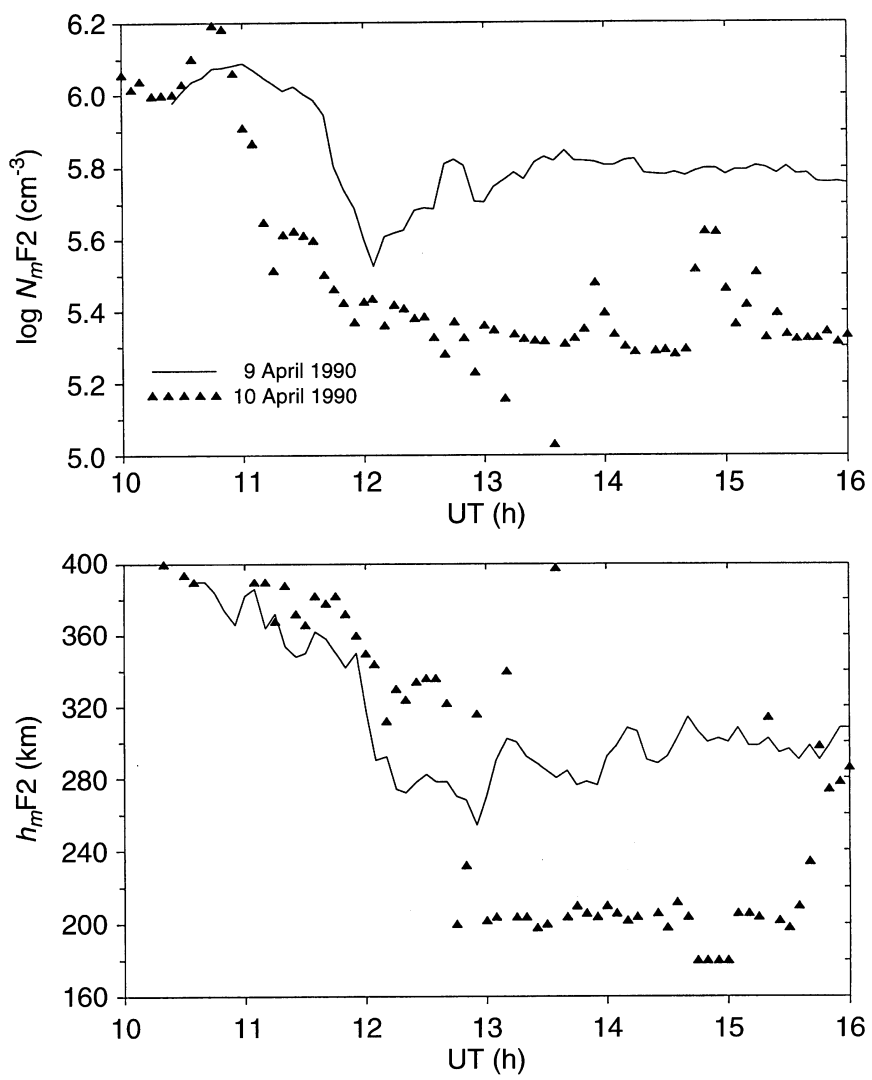

Fig. 2. Same as Fig. 1 but for the period 9-10 April 1990

this case $N_{m} \mathrm{~F} 2$ was reduced by a factor of 6.4 , and $h_{m} \mathrm{~F} 2$ increased by about $40 \mathrm{~km}$. On 10 April 1990 a large decrease in both $N_{m} \mathrm{~F} 2$ and $h_{m} \mathrm{~F} 2$ was observed. Figure 2 shows a normal negatively disturbed F2 layer around 1230 UT which is then split into two layers. After 1300 UT the ionosphere was characterized by one layer with a peak around $200 \mathrm{~km}$ height.

Electron density profiles resulting from our model calculations in comparison with observed $N_{e}(h)$ profiles for the two periods in question are displayed in Figs. 3 and 4 (upper panels). The lower panels show a comparison of the calculated $\left[\mathrm{O}^{+}\right] / N_{e}$ ratio with the EISCAT ion composition model used for the routine incoherent data reduction. The calculated height variations for $\left[\mathrm{O}^{+}\right] / N_{e}$ are close to the standard EISCAT ion composition model for quiet days (1, 2 April 1992), and therefore no correction was applied for the measured $N_{e}(h), T_{e}(h)$, and $T_{i}(h)$ profiles. For disturbed days, however, the calculated ion composition differs significantly from the standard EISCAT model. A strong enrichment of the ionosphere with molecular ions even at heights of the F2 layer required a correction of the measured $N_{e}(h), T_{e}(h)$, and $T_{i}(h)$ profiles for these days as outlined in Mikhailov and Schlegel (1997).

\section{Discussion}

Figures 3 and 4 show that our model calculations describe the observed $N_{e}(h)$ profiles with good accuracy
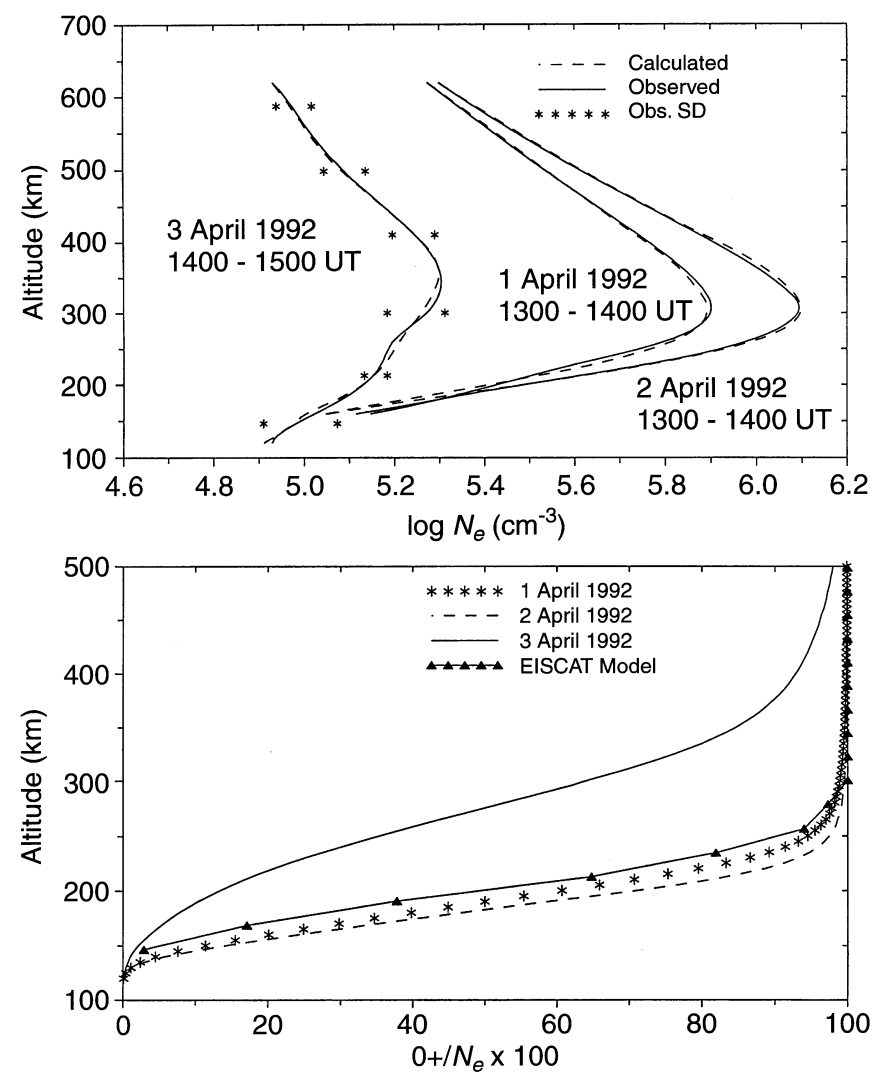

Fig. 3. Top panel: observed (together with a band of standard deviations) and calculated $N_{e}(h)$ profiles for two geomagnetically quiet (1, 2 April) and disturbed (3 April 1992) days. Bottom panel: calculated and EISCAT model $\left[\mathrm{O}^{+}\right] / N_{e}$ height variations for the 3 days

for quiet as well as for disturbed conditions. So we can conclude that the considered set of main physical processes in the model is sufficient for the description of the sunlit auroral F2 region even during such disturbed conditions. These are the same processes commonly used for mid-latitude F2-layer modelling. Similar conclusions were obtained by Farmer et al. (1984) and Lathuillere and Brekke (1985) analyzing EISCAT observations.

The observed negative storm effect on 3 April 1992 looks much like mid-latitude events with reduced $N_{m} \mathrm{~F} 2$ and increased $h_{m} \mathrm{~F} 2$ values, but the mechanism causing it turns out to be different. The calculated relative variations of the neutral composition during the 31 March - 3 April period (Fig. 5, left panel) are not strong. This may be attributed to the fact that the considered period (1415 UT) was relatively close to the beginning of the geomagnetic storm at about 10 UT. Much more time is usually required for changes in the neutral composition. Nevertheless a pronounced difference in the shape of the $T_{n}(h)$ profile can be already seen for this period (Fig. 6, left panel): The calculated shape parameter is $S=0.035$ $\mathrm{km}^{-1}$, while MSIS-83 gives $S=0.017 \mathrm{~km}^{-1}$ as for the previous quiet days. The increased value of $S$ results from the strong Joule heating which took place for the period in question. Figure 6 shows two $T_{n}(h)$ profiles together with the observed $T_{i}(h)$. The unusual $T_{i}(h)$ 

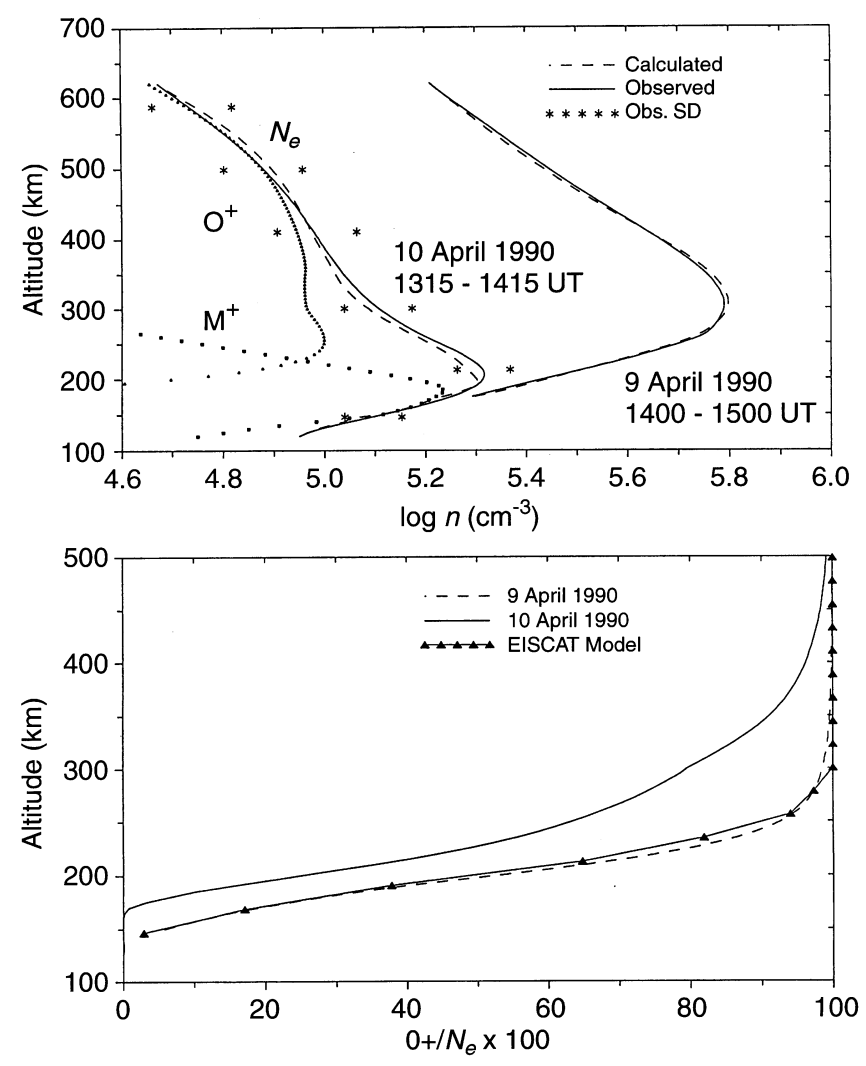

Fig. 4. Same as Fig. 3 but for 9-10 April 1990. Calculated atomic oxygen and molecular ion concentrations are shown as well (in the upper panel)

profile below $200 \mathrm{~km}$ clearly indicates the strong frictional heating in this height range. Our method is indeed sensitive enough to reproduce such changes in the shape of $T_{n}(h)$.

The observed strong $N_{m} \mathrm{~F} 2$ reduction from 2 to 3 April 1992 (by a factor of up to 6.4) does not result from neutral composition changes: the $\mathrm{O} / \mathrm{N}_{2}$ ratio equals 5 on 2 April and 4.7 on 3 April at the $h_{m} \mathrm{~F} 2$ height. Also, Fig. 5 reveals only small neutral composition changes at $300 \mathrm{~km}$ altitude. On the other hand, the linear loss coefficient $\beta=\gamma_{1}\left[\mathrm{~N}_{2}\right]+\gamma_{2}\left[\mathrm{O}_{2}\right]$ for $\mathrm{O}^{+}$ions increased by a factor of 5 at the F2-layer maximum height. This results from a large increase in $\gamma_{1}$ by more than a factor of 10 due to its dependence on the electric field (Schunk et al., 1975). Therefore, the very large negative F2-layer storm effect on 3 April 1992 is mainly a consequence of the strong electric field $(\boldsymbol{E} \approx 85 \mathrm{mV} / \mathrm{m})$, rather than of changes in neutral composition. In principle, an additional contribution to the $N_{m} \mathrm{~F} 2$ reduction can originate from a strong downward plasma drift (Fig. 5, lower left panel). Under normal conditions the vertical plasma drift can be fully attributed to the meridional thermospheric wind $V_{n x}$ (Farmer et al., 1984), as the magnetic field line declination at Tromso is only $1.24^{\circ}$ and the zonal wind component, $V_{n y}$ is not efficient at least for near-noon hours when it is small. The calculated strong downward drift of $40 \mathrm{~m} / \mathrm{s}$ on 3 April (Fig. 5, lower left panel) however, can hardly be attributed to a northward wind of $\approx 180 \mathrm{~m} / \mathrm{s}$, but may partly be explained by a geometrical effect proposed by Schlegel (1986): if the line-of-sight velocity measured by the radar and interpreted as $V_{l}$ is not exactly parallel to $\boldsymbol{B}$ on a local scale (especially during geomagnetic disturbances), a component of the perpendicular ion velocity, $V_{\text {perp }}$, can map into the line-of-sight velocity. Even if the deviation from the parallel direction is only of the order of $1^{\circ}$, a large perpendicular ion velocity of $1700 \mathrm{~m} / \mathrm{s}$ (as we have for 3 April) can easily give a contribution of several $10 \mathrm{~m} / \mathrm{s}$ to the measured line-of-sight velocity, falsely assumed to be parallel to $\boldsymbol{B}$. Therefore we assume that the calculated strong downward drift on 3 April 1992 may have - at least partly - a geometrical rather than a geophysical explanation.

The observed steep upsurge of the electric field produced not only a negative disturbance at the latitudes of EISCAT, but also a daytime trough in the latitudinal distribution of $N_{m} \mathrm{~F} 2$. Figure 7 shows the observed latitudinal variation of $N_{m} \mathrm{~F} 2$ along a chain of European ionosonde stations for the same time-interval. The disturbance due to the high-latitude electric field is seen to extended down to latitudes of Uppsala $\left(\Phi=58^{\circ}\right)$, and a small $N_{m} \mathrm{~F} 2$ reduction is seen even at the mid-latitude station Kaliningrad. Therefore 3 April provides an excellent example of a daytime trough formation due to an enhanced electric field. The observed effect resembles a polarization jet first reported by Galperin et al. (1973) but is not identical to so-called SAID events [subauroral ion drift, see Anderson et al. (1991) for details].

The considered case of 3 April 1992 demonstrates a pure effect of increased electric field without any noticeable changes in thermospheric parameters, as the analyzed period was just at the beginning of the geomagnetic storm. The case of 10 April 1990 already represents the second day of a severe geomagnetic storm with strong worldwide F2-layer negative storm effects (e.g. Buonsanto et al., 1992). A complete disappearance of the F2-layer maximum at the usual heights implies strong changes in the thermosphere, as was shown by Mikhailov and Foster (1997) using Millstone Hill observations for that day.

Figure 4 (top panel) shows that the observed ionospheric maximum around $200 \mathrm{~km}$ results from the superposition of two layers: a normal F1 layer at 175 $\mathrm{km}$ composed of molecular ions and a strongly reduced and distorted F2 layer composed of $\mathrm{O}^{+}$ions. Similar to the previous case, the ionosphere on 10 April 1990 is enriched with molecular ions even at F2-layer heights. As we do not have a real quiet reference day, we can only compare 10 April with 9 April. The latter looks like a normal day with undisturbed ion composition (Fig. 4, bottom), although in fact it was a disturbed day as well (Table 1). The analysis has revealed that the main reason for the strong F2-layer depletion is the decrease in atomic oxygen concentration by a factor of 4.3 at $300 \mathrm{~km}$ altitude, accompanied by increased $\left[\mathrm{N}_{2}\right]$ and $\left[\mathrm{O}_{2}\right]$ (Fig. 5, top right). Both, the increase in $\left[\mathrm{N}_{2}\right]$ and $\left[\mathrm{O}_{2}\right]$ and in $\gamma_{1}$ due to enhanced temperature, and a high electric field result in an increment in the linear loss coefficient $\beta=\gamma_{1}\left[\mathrm{~N}_{2}\right]+\gamma_{2}\left[\mathrm{O}_{2}\right]$ on 10 April with respect 

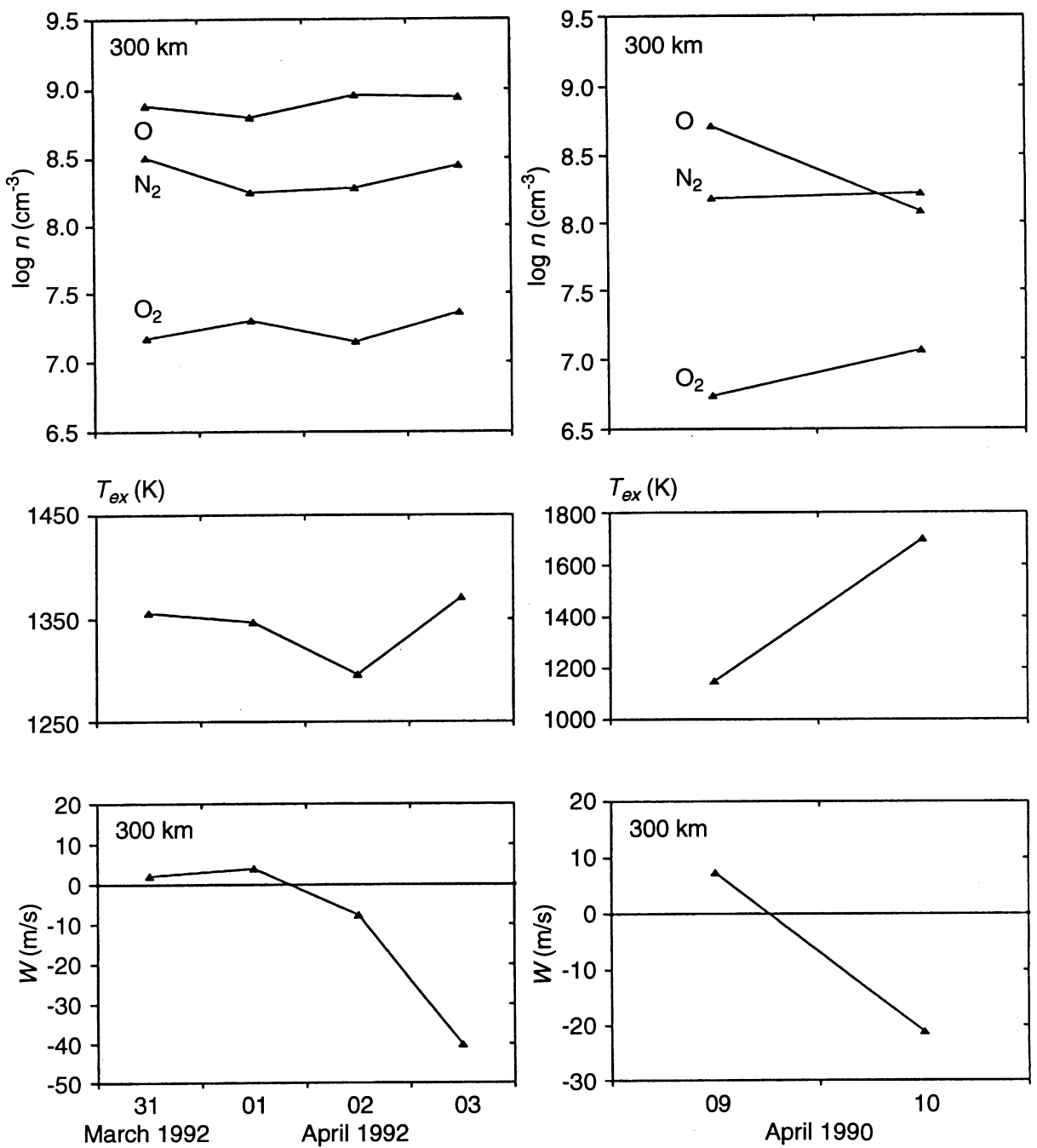

Fig. 5. Calculated neutral composition (at $300 \mathrm{~km}$ ) and exospheric temperature $T_{\mathrm{ex}}$ (top and middle panels) and calculated vertical plasma drift (bottom panel) for 31 March-3 April 1992 (left) and 09-10 April 1990 (right) to 9 April (by a factor of 1.6). This type of neutral composition changes is typical of the auroral zone where Joule heating results in atmospheric upwelling followed by a decrease in light atmospheric species and an increase in heavy species (e.g., Prölss and Fricke,1976; Trinks et al., 1976; Prölss, 1991). An additional reduction of $\left[\mathrm{O}^{+}\right]$can be caused again by a downward plasma drift. As in the 10 April 1990 case the calculated downward drift of $21 \mathrm{~m} / \mathrm{s}$ hardly can be fully attributed to $\mathrm{a} \approx 100 \mathrm{~m} / \mathrm{s}$ northward thermospheric wind, since usually a southward circulation is expected for disturbed days. Again the observed northwest ion drift $(700 \mathrm{~m} / \mathrm{s})$ can easily give a contribution of several $\mathrm{m} / \mathrm{s}$ to the measured downward line-of-sight plasma velocity.

Both the height of the $N_{e}(h)$ maximum around $200 \mathrm{~km}$, and the value of the electron concentration in the peak are determined by the height distribution of neutral gas concentrations. Large changes in the $T_{n}(h)$ profile are required to fit the observed $N_{e}(h)$ profile. A very low value of the shape parameter, $S=$ $0.0055 \mathrm{~km}^{-1}$ instead of $0.016 \mathrm{~km}^{-1}$ predicted by MSIS83 , and a reduced neutral temperature at $120 \mathrm{~km}$ $\left(T_{120}=385 \mathrm{~K}\right.$ instead of $515 \mathrm{~K}$ from MSIS-83) resulted from the $N_{e}(h)$ fitting procedure, while $T_{\text {ex }}$ is close to the MSIS-83 prediction (Fig. 6, right panel). The observed $\mathrm{T}_{\mathrm{i}}(\mathrm{h})$ has a similar slope around $200 \mathrm{~km}$ height, confirming the obtained result of the low $\mathrm{S}$ value. Such a $T_{n}(h)$ profile results in a moderate $\left[\mathrm{O}_{2}\right]$ and $\left[\mathrm{N}_{2}\right]$ increase at $300 \mathrm{~km}$ height despite the $600-\mathrm{K}$ increase in $T_{\text {ex }}$ (Fig. 5, right panel).

A small value of $S\left(0.011-0.013 \mathrm{~km}^{-1}\right.$ with respect to the MSIS- 83 predicted $S=0.017 \mathrm{~km}^{-1}$ ) was obtained for the same day, 10 April 1990 from the Millstone Hill data analysis (Mikhailov and Foster, 1997). Therefore the results of our calculations show a pronounced decrease in the neutral temperature in the lower thermosphere for this severe geomagnetic storm. We propose that this $T_{n}$ decrease results from the enhanced atmospheric cooling trough nitric oxide (Richards et al.,1982; Gerard and Roble, 1988). The increase of nitric oxide concentration during disturbed periods is well documented (e.g., Rush, 1973; Barth, 1989; Siskind et al.,1989 a,b). It should be mentioned that the MSIS83 model shows a tendency for the $S$ parameter to decrease with growing geomagnetic activity level represented by the Ap index. The 10 April 1990 storm was a unique event with Ap $=124$ which cannot be properly described by an empirical model like MSIS- 83 .

We have solely used the long-pulse EISCAT results in this paper. A comparison of these data and CP1 

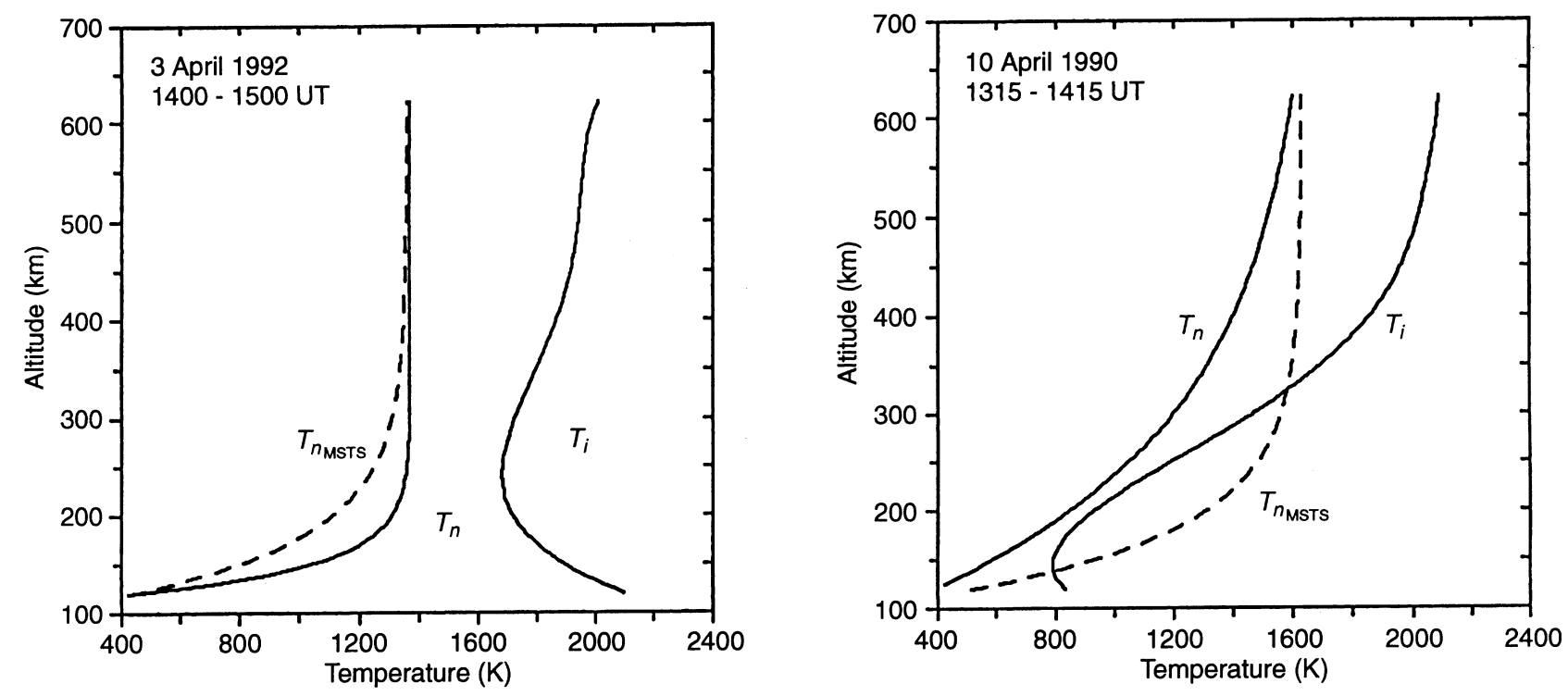

Fig. 6. Calculated and MSIS- $83 T_{n}(h)$ profiles together with the observed $T_{i}(h)$ profile for the disturbed days 3 April $1992(l e f t)$ and 10 April 1990 (right)

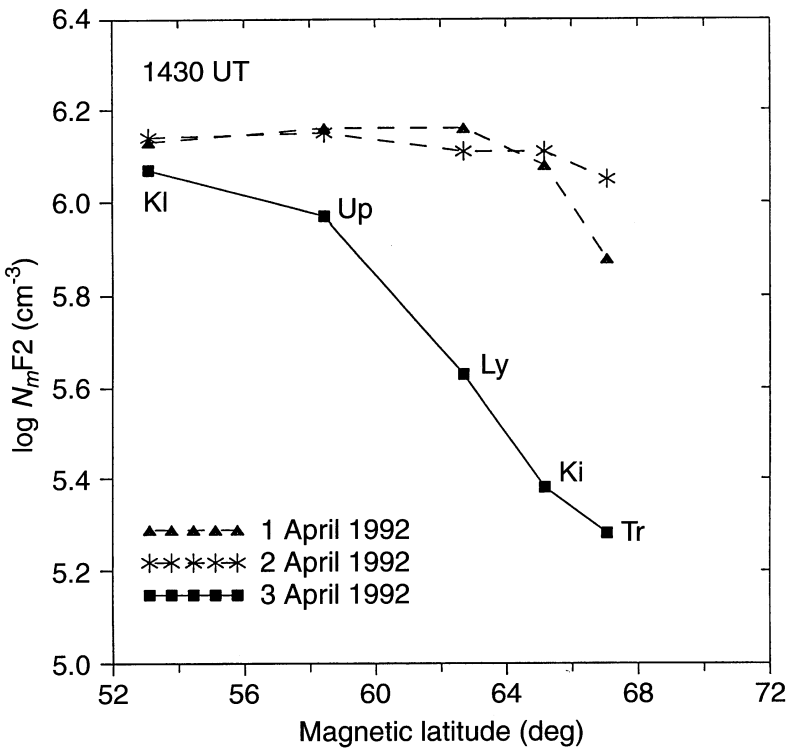

Fig. 7. Observed $N_{m} \mathrm{~F} 2$ latitudinal variation for the chain of European ionosonde stations: Kaliningrad, Uppsala, Lycksele, Kiruna and Tromso (EISCAT location)

multipulse data with their finer height resolution below $260 \mathrm{~km}$ has shown a noticeable difference between the two sets of results. A systematic study of the cause of these differences is beyond the scope of this paper. The fact is that the multipulse data above $200 \mathrm{~km}$ often suffer from bad signal-to-noise ratio. The long-pulse data on the other hand may be unreliable below about $180 \mathrm{~km}$ because the pulse length (corresponding to about $40 \mathrm{~km}$ ) does not adequately match the scale height of E-region structures. Since in our model the parameters $N_{e}(h), T_{i}(h), T_{e}(h)$, and $V_{l}(h)$ are most important at F2region heights, we restricted our analysis to the longpulse data.
It should also be noted that non-Maxwellian effects in the ion velocity distribution which become important in the presence of large electric fields have not been considered in our study. It is well known that these effects give rise to systematic errors in the interpretation of incoherent-scatter spectra [see Hubert et al. (1996) for a recent review]. For field-aligned measurements as in the case of CP-1, however, these effects should be small even at electric fields of $85 \mathrm{mV} / \mathrm{m}$ (3 April 1992). The resulting uncertainties are within the overall error limits of our method which are discussed in Mikhailov and Schlegel (1997).

\section{Summary}

A self-consistent method for daytime F-region modelling has been applied to EISCAT observations during two disturbed periods with a strong $N_{e}$ decrease at F2layer heights. The main results of our analysis can be summarized as follows:

1. The large negative F2-layer storm effect on 3 April 1992 with an $N_{m} \mathrm{~F} 2$ reduction by a factor of 6.4 compared to the previous quiet period, is mostly due to strong electric field $(\boldsymbol{E} \approx 85 \mathrm{mV} / \mathrm{m})$, rather than to changes in neutral composition. This is attributed to the fact that the considered period was only about $4 \mathrm{~h}$ later than the storm onset. Additional contribution to the $N_{m} \mathrm{~F} 2$ reduction can result from a strong downward plasma drift, although it is uncertain how much of this is due to geometrical effects. This is different from midlatitude F2-layer storms where the vertical plasma drift is usually more positive due to enhanced equatorward thermospheric wind.

2. Unlike the 3 April 1992 case, the strong negative storm effect on 10 April 1990 with a complete disappearance of the F2-layer maximum at usual heights is 
mainly attributed to changes in neutral composition and temperature. Three processes are responsible for the observed F2-layer depletion: a reduction in [O] (by a factor of 4.3) causes a corresponding reduction of the $\mathrm{O}^{+}$production rate; the increase in $\left[\mathrm{O}_{2}\right],\left[\mathrm{N}_{2}\right], T_{e x}$, and electric field provide a substantial growth in the linear loss coefficient $\beta=\gamma_{1}\left[\mathrm{~N}_{2}\right]+\gamma_{2}\left[\mathrm{O}_{2}\right]$ for $\mathrm{O}^{+}$ions and finally a downward plasma drift.

3. The appearance of the ionospheric maximum around $200 \mathrm{~km}$ height is the result of the superposition of two layers: a normal F1 layer at $175 \mathrm{~km}$ and a depleted and distorted F2 layer with a maximum around $260 \mathrm{~km}$ height. The positions of both maxima are strongly controlled by the neutral composition, and a very small value of the shape parameter $(S=$ $0.0055 \mathrm{~km}^{-1}$ ) for the neutral temperature profile was required to fit the observed $N_{e}(h)$.

4. A small value of the shape parameter $\mathrm{S}$ and a low neutral temperature at $120 \mathrm{~km}\left(T_{120}=385 \mathrm{~K}\right.$ instead of $515 \mathrm{~K}$ predicted by MSIS-83) indicate strong cooling of the lower thermosphere. We propose that this cooling is due to enhanced nitric oxide concentration usually observed at these heights during geomagnetic storms.

Acknowledgements. The authors thank the Director and the staff of EISCAT for running the radar and providing the data. The EISCAT Scientific Association is funded by scientific agencies of Finland (SA), France (CNRS), Germany (MPG), Japan (NIPR), Norway (NF), Sweden(NFR), and the United Kingdom(PPARC). A.M. is grateful to the Max-Planck-Gesellschaft for a research stipend at the MPAE.

Topical Editor D. Alcaydé thanks U. Lovhaug and another referee for their help in evaluating this paper.

\section{References}

Anderson, P. C., R. A. Heelis, and W. B. Hanson, The ionospheric signatures of rapid subauroral ion drifts, J. Geophys. Res., 96, 5785-5792, 1991.

Barth, C. A., Reference models for thermospheric NO, Hand MAP, 31, 1, 132-144, 1989.

Buonsanto, M. J., J. C. Foster, and D. P. Sipler, Observations from Millstone Hill during the geomagnetic disturbances of March and April 1990, J. Geophys. Res., 97, 1225-1243, 1992.

Farmer, A. D., M. Lockwood, R. B. Horne, B. J. I. Bromage, and K. S. C. Freeman, Field-perpendicular and field-aligned plasma flows observed by EISCAT during a prolonged period of northward IMF, J. Atmos. Terr. Phys., 46, 473-488, 1984.
Galperin, Y. I., Y. N. Ponomarev, and A. G. Zosinova, Direct measurements of ion drift velocity in the upper atmosphere during a magnetic storm, Cosmicheskie Issled, 11, 273-283, 1973.

Gérard, J.-C., and R. G. Roble, The role of nitric oxide on the zonally averaged structure of the thermosphere: solstice conditions for solar cycle maximum, Planet. Space Sci., 36, 271-279, 1988.

Hubert, D., F. Leblanc, and P. Galmard, Current state-of-the-art for the measurements of non-Maxwellian plasma parameters with the EISCAT UHF facility, Ann. Geophysicae, 14, 15061512,1996

Lathuillere, C., and A. Brekke, Ion composition in the auroral ionosphere as observed by EISCAT, Ann. Geophysicae, 3, 557568, 1985.

Mikhailov, A. V., and J. C. Foster, Daytime thermosphere above Millstone Hill during severe geomagnetic storm, J. Geophys. Res., 102, 17 275-17 282, 1997.

Mikhailov, A. V., and K. Schlegel, Self-consistent modelling of the daytime electron density profile in the ionospheric $\mathrm{F}$ region, Ann. Geophysicae, 15, 314-326, 1997.

Prölss, G. W., Thermosphere-ionosphere coupling during disturbed conditions, J. Geomagn. Geoelectr., 43, 537-547, 1991.

Prölss, G. W., Ionospheric F-layer storms, In Handbook of atmospheric electrodynamics, Vol.2, Ed. H. Volland, CRC Press, Boca Raton, pp. 195-248, 1995.

Prölss, G. W., and K. H. Fricke, Neutral composition changes during a period of increasing magnetic activity, Planet. Space Sci., 24, 61-67, 1976.

Richards, P. G., M. R. Torr, and D. C. Torr, The seasonal effect of nitric oxide cooling on the thermospheric UV heat budget, Planet. Space Sci., 30, 515-518, 1982.

Rush, D.W., Satellite ultraviolet measurements of nitric oxide fluorescence with a diffusive transport model, J. Geophys. Res., 78, $5676-5686,1973$.

Schlegel, K., The study of tides and gravity waves with the help of field-aligned velocities measured by EISCAT, J. Atmos. Terr. Phys., 48, 879-886, 1986.

Schunk, R. W., W. J. Raitt, and P. M. Banks, Effect of electric fields on the daytime high-latitude $\mathrm{E}$ and $\mathrm{F}$ regions, J. Geophys. Res., 80, 3121-3130, 1975.

Siskind, D. E., C. A. Barth, D. A. Evans, and R. G. Roble, The response of thermospheric nitric oxide to an auroral storm 1. Low and middle latitudes, J. Geophys. Res., 94, 16885-16898, 1989a.

Siskind, D. E., C. A. Barth, D. A. Evans, and R. G. Roble, The response of thermospheric nitric oxide to an auroral storm 2. Auroral latitudes, J. Geophys. Res., 94, 16899-16911, $1989 \mathrm{~b}$.

Trinks, H., S. Chandra, N. W. Spencer, and U. von Zahn, A twosatellite study of the atmosphere response to a major geomagnetic storm, J. Geophys. Res., 81, 5013-5017, 1976. 